\title{
Market survey and analysis of "new dream" training for new generation industrial workers
}

\author{
Liao Yuan-bing
}

(Heyuan Polytechnic, Heyuan, Guangdong, 517000)

\author{
Key words: A dream plan; New generation industrial workers; The cultivation of the status \\ quo; market research
}

\begin{abstract}
The "dream program" of the new generation industrial workers, led by the Communist Youth League Guangdong Provincial Committee and other units, has set up a good platform for the growth and development of the new generation of industrial workers. Since the implementation of the "dream project", the scale of the school has been growing steadily, the school running mode has been innovating constantly, and the quality of running schools has been continuously improved, and the expected good results have been achieved. However, due to the comprehensive influence of various factors such as enterprises, employees and schools, there are still some shortcomings in running schools. To carry out the "dream project" to train the new generation of industrial workers, the purpose of the market investigation and analysis is to provide a scientific basis for better running the project.
\end{abstract}

\section{Introduction}

The new generation of industrial workers is the product of the development and evolution of migrant workers in the new situation. It is imperative to carry out targeted education for the huge group of new generation industrial workers in the new era.

\section{The significance of the "Dream Project" to train the new generation of industrial workers}

To help the new generation of young workers to better integrate into society and grow into talents, the Guangdong Provincial Committee of the Communist Youth League and Peking University jointly launched the "Dream Project - The New Generation of Industrial Workers in Guangdong Province" in $2010^{[1]}$. The implementation of the "Dream Project" program to train new generations of industrial workers has great practical significance, which is mainly reflected in these aspects:

For the new generation of industrial workers, it undoubtedly provides a good platform for improving their overall quality and ability, which is conducive to the improvement of the comprehensive competitiveness of the new generation of industrial workers. The "Dream Project" meets the national development and the new generation. The needs of the individual development of migrant workers have promoted educational equity and improved people's livelihood ${ }^{[2]}$.

For the new generation of industrial groups, it is conducive to changing the current situation of the lower quality of the new generation of industrial workers and the low level of education, and promote the social contribution of the new generation of industrial workers to a new level;

For the enterprises, the new generation of industrial workers mainly serve enterprises, and upgrading the quality of new generation industrial workers will ultimately promote the development of enterprises;

For the society, the new generation of industrial workers is an important part of society, and it is the most active group. Training new generations of industrial workers is conducive to the construction of a harmonious society. The implementation of the "Dream Project" has further expanded the coverage of public services and strengthened the trend of public policies to accelerate social integration ${ }^{[3]}$.

In short, it is necessary and urgent to implement the "Dream Project" program to train new generations of industrial workers in the new era. The purpose of the market research on the 
development of the new generation of industrial workers in the "Dream Project" program is to promote the scientific development of the people's livelihood project and ensure the quality and efficiency of the training.

\section{3. "Dream Project" to train the new generation of industrial workers market survey and analysis}

In order to more comprehensively, deeply and objectively understand the implementation of the "Dream Project" to train the new generation of industrial workers, and grasp the needs and requirements of the new generation of industrial workers, and in order to further improve the pertinence and effectiveness of the project, the author goes deep into the new generation industrial workers and issues 1,000 questionnaires, 972 were returned, and 967 valid questionnaires. The effective recovery rate of the questionnaire was $96.7 \%$. In this survey, the questionnaire about the status quo of the "Dream Project" to train the new generation of industrial workers was set up, which consists of multiple-choice questions, fill-in-the-blank questions and quiz questions.

\subsection{Overview of the new generation of industrial workers}

The basic situation of the new generation of industrial workers in this survey is as follows:

Gender age: In the survey, there are $42 \%$ of male workers in the new generation of industrial workers and $58 \%$ of women. The age is basically in the range of 18-35 years old, of which 18-25 years old accounted for 31\%, 25-30 years old accounted for 47\%, 30-35 years old accounted for $19 \%$, and other age groups accounted for $3 \%$.

Obtaining academic qualifications and levels: More than $80 \%$ of the new generation of industrial workers receive education through ordinary full-time education. Only less than $20 \%$ of the new generation of industrial workers receive education through adult education level; in the highest level of education obtained, below junior high school level education accounted for $7 \%$, junior high school level education accounted for $36 \%$, high school secondary school accounted for $38 \%$, university specialists accounted for $9 \%$, university undergraduate accounted for $6 \%$, graduate students accounted for $5 \%$.

Household registration: people with household registration in Guangdong Province accounted for $42 \%$, and the other with household registration outside Guangdong Province accounted for 58\%. Among those with household registration in Guangdong, rural household registration accounted for $69 \%$, urban household registration accounted for $31 \%$, and among households whose household registration was not in Guangdong, rural household registration accounted for $72 \%$, and urban household registration accounted for $28 \%$.

Family situation: there are $55 \%$ of newly-invested industrial workers married and $45 \%$ unmarried in this survey; among those who are married, $42 \%$ with one child, $42 \%$ with two children, and $12 \%$ with 3 or more children.

Working industry situation: the surveyed new generation of industrial workers mainly engaged in industries including computers, home appliances, mobile network communications, e-commerce, education and training, electronic information, finance, securities, insurance, trade, sales, cosmetics, clothing, furniture, toys, office supplies and equipment, machinery, automobiles, medicine, etc.

Occupation: The major occupations of the newly-invested industrial workers surveyed include production, sales, marketing, public relations, customer service, administration, logistics, human resources, finance, auditing, clerical, technical, research and development, management, teachers, consultants, consulting, professional technology, self-employed, self-employed, etc.

Working years and income: the new generation of industrial workers surveyed accounted for $8 \%$ with the work experience within one year, 29\% with 1-3 years, 34\% with 3-5 years, and $29 \%$ with more than 5 years; The income is 1000-2000 yuan, which accounted for 3\%, 2000-3000 yuan, which accounted for 42\%, 3000-4000 yuan, which accounted for 47\%, and 4,000 yuan or more, which accounted for $8 \%$.

Stable work situation: $18 \%$ of the new generation of industrial workers surveyed working in the same city within one year, $45 \%$ in $1-3$ years, $26 \%$ in $3-5$ years, and $11 \%$ in 5 years; $38 \%$ in one year 
of work in the same unit, $36 \%$ in $1-3$ years, $27 \%$ in $3-5$ years, $9 \%$ in 5 years or more; $27 \%$ in one city, $48 \%$ have worked in two cities, and $25 \%$ have worked in three or more cities.

\subsection{The participation of new generation industrial workers in the "Dream Project"}

The survey found that the basic situation of the new generation of industrial workers participating in the "Dream Project" is as follows:

Participation: $64 \%$ of the new generation of industrial workers surveyed participated in the "Dream Project", which was less in 2010-2012. The participants were mainly concentrated in 2013-2017, and the respondents in school are currently in "Dream Project" is accounted for 29\%.

Graduation: $57 \%$ of the years spent on the "Dream Project" to obtain a diploma, $36 \%$ in three years, and $7 \%$ in three years. The main reason for not being able to graduate within the required length of school is work. I am busy with learning, work changes, etc.

Fees: The total tuition fee for the "Dream Project" involved in the survey is basically 5,000 yuan. During the period, the individual tuition fee is only 1,000 yuan. Other expenses are supported by provincial finance and municipal finance.

Demand situation: The level of "Dream Project" requires $70 \%$ of the specialists and $30 \%$ of the undergraduate courses; professional workers with economic management, science and engineering majors such as accounting, business management, computer, application electronics, mold design and manufacturing were demand in a large number.

The "Dream Project" enhances the form of academic qualifications: At present, the respondents believe that the "Dream Project" continuing education form is the adult college entrance examination, online education and radio and television universities.

Sources of information: The new generation of industrial workers surveyed to understand and master the "Dream Project" project mainly includes fellow introduction, colleague's introduction, company publicity, university and teaching point publicity, government and party group documents, online publicity, media reports, WeChat publicity, newspaper announcements, etc.

\subsection{The value of the new generation of industrial workers on the "Dream Project"}

In the background of the "Dream Project": the surveyed new-generation industrial workers who were satisfied with the current job before participating in the "Dream Project" accounted for 37\%, who were dissatisfied with the current job accounted for $63 \%$, and who believed that they still adhered to active learning after the work accounted for $26 \%$. After being working, the workers that only learn the knowledge necessary to study work accounted for $21 \%$, students who do not study charging after work accounted for 53\%; who think they have insufficient knowledge accounted for $22 \%$, who think that skills are not high accounted for $17 \%$, and who think they have insufficient academic qualifications accounted for $61 \%$. those who are satisfied with current life accounted for $18 \%$, who are generally satisfied accounted for $37 \%$, and who are dissatisfied accounted for $45 \%$.

Purpose of participating in the "Dream Project" education: Some new generation of industrial workers are to broaden their knowledge, increase their knowledge, enhance their individual competitiveness, and expand their interpersonal circle; some are to obtain a certain degree and diploma, cheap tuition, easy to learn, and Find better jobs, improve the lives of yourself and your family; others are because of occasional participation, no specific purpose is just a rise, not the initiative to participate, but the organization.

Feelings of participating in the "Dream Project": 29\% of the participants satisfied with educational resources, $44 \%$ much satisfied, $27 \%$ unsatisfied; $37 \%$ satisfied with the professional setting of the school, $47 \%$ satisfied, $16 \%$ dissatisfied; $30 \%$ satisfied with the school's curriculum, $41 \%$ satisfied, $29 \%$ dissatisfied; $29 \%$ satisfied with the teaching level of teachers, $37 \%$ satisfied, $34 \%$ are dissatisfied; $38 \%$ are satisfied with the school's management services, $48 \%$ are satisfied, $14 \%$ are dissatisfied; $17 \%$ are satisfied with the school's extracurricular activities, and $26 \%$ are satisfied. $57 \%$ of the students are dissatisfied; $36 \%$ are satisfied with the entrance examinations of the school, $49 \%$ are satisfied, $15 \%$ are dissatisfied; $40 \%$ are satisfied with the graduation thesis of the school, and $42 \%$ much satisfied, $18 \%$ unsatisfied.

The feelings of the organization of the "Dream Project" extracurricular activities: It is believed 
that sports competitions, outdoor outings, expert lectures, interest discussions, public welfare activities, etc. are mainly carried out, and 5\% of those activities are satisfied, and $27 \%$ are satisfied. It is considered to be $46 \%$ in general and $22 \%$ are in unsatisfied.

Participation in the "Dream Project": participants believe that participating in the "Dream Project" greatly enrich their knowledge accounted for $27 \%, 46 \%$ think their knowledge is increased, $19 \%$ think normal increase, and $8 \%$ little increase; $18 \%$ of the participants thinks their skills greatly increase, 36\% think large increase, 29\% think normal increase, $17 \%$ considered little increase; participants think that participating in the "Dream Project" help largely expand the circle of interpersonal contacts are accounted for $30 \%, 48 \%$ think their circle of interpersonal contacts are expend, $18 \%$ are normally expend, and $4 \%$ are little expend; participants think that participating in the "Dream Project" makes the large overall improvement of personal quality accounted for $21 \%$, $47 \%$ are much improved, and $20 \%$ considered normal degree improvement, $12 \%$ think less improvement.

\subsection{Evaluation and suggestion of the new generation of industrial workers on the "Dream Project"}

The performance of the groups in the implementation of the dream project: $73 \%$ of the groups' work is serious and responsible, and $27 \%$ are normal; $16 \%$ of the groups' communication between the group and the students is very frequent, and $24 \%$ of the groups' communication is frequent. $41 \%$ communication frequency is normal, and the groups that lack of communication accounted for 19\%; the group organization and the university (teaching point) that communicated very frequently accounted for $23 \%$, and the group with frequent communication accounted for $34 \%$, and $33 \%$ frequency is normal, $10 \%$ with less communication. The group organization is very concerned about the students' study, work and life accounted for $15 \%, 26 \%$ of the groups is much concerned, and $42 \%$ are in normal degree concern, and $17 \%$ are not concerned enough.

The "Dream Project" program carries out the performance of secondary schools: $37 \%$ of schools thought the fees are very regulated. $46 \%$ think the fees are more standardized, $17 \%$ think the fees are irregular, and irregular fees are mainly occurred in private teaching institutions; $55 \%$ of those institutions thought the fees are considered to be very frequent in communication between schools and students, $25 \%$ think the fees are considered to be more frequent, and $11 \%$ think the fees are considered to be in general, $9 \%$ think that there is a lack of communication; $35 \%$ of those school think that the school is concerned about the students' study, work, and life, $42 \%$ with the more concerned, and $17 \%$ think that is general, $6 \%$ think it's not care enough; $27 \%$ of the students' management practices are in good condition, $46 \%$ are better, and $16 \%$ are considered to be generally good, $11 \%$ considered it is unsatisfied.

Suggestions for the overall implementation of the "Dream Project": The main recommendations include further reducing the burden of tuition and fees, increasing the scope of autonomy, enriching the curriculum, optimizing curriculum, optimizing teaching staff, strengthening offline learning activities and communication, and increasing field visits. Learning and so on.

Suggestions to the Youth League Committee and the government: increase financial input, expand similar public welfare projects, maintain the continuity of the implementation of the project, enrich extracurricular activities, and strengthen the multi-party communication between government school employees.

\section{Analysis of the problems existing in the "Dream Project" training the new generation of industrial workers}

Guangdong is a major gathering place for the new generation of industrial workers in the country. Although the current education and training of the new generation of industrial workers in Guangdong Province has achieved certain results, there are still many problems ${ }^{[4]}$. From the above survey and analysis, it can be seen that the "Dream Project" trains the new generation of industrial workers mainly have the following problems: 


\subsection{Asymmetry of beneficiary objects}

The number of new generation industrial workers in Guangdong is huge, and the demand for the "Dream Project" is huge. Due to various subjective and objective factors, many of the environment and conditions of the new generation of industrial workers, industry specificity and other factors have not been able to reach the "Dream Project", the asymmetry of this resource sharing limits this group cannot participate in " Dream Project."

\subsection{The utilitarianity of participating in the purpose}

The survey shows that there are still a large number of new-generation industrial workers who participate in the "Dream Project" only for obtaining a diploma, some people are blindly participating, and the purpose of the "Dream Project" education is not fully understood, unscientific, and inaccurate. It is difficult for utilitarian and blind participants to achieve the purpose of project implementation through learning.

\subsection{Project development lack of effectiveness}

In the investigation of the project implementation, it was found that the beneficiaries thought that the growth of knowledge was not much accounted for $27 \%$. The beneficiaries that thought the improvement of skills was not large were accounted for $46 \%$. The beneficiaries that overall evaluation considered the effect was small accounted for $32 \%$, showing that the effectiveness of the project is not strong enough.

\subsection{Project satisfaction is not high enough}

During the implementation of the "Dream Project", the new generation of industrial workers have certain dissatisfaction with the integration of educational resources, the rationality of professional settings, the management services, the entrance examinations, and the guidance of graduation thesis, while the curriculum is arranged and teachers are taught. The situation and the organization of extracurricular activities are not satisfied.

\subsection{Communication needs to be strengthened}

The investigation and feedback show that there is still a situation in which the communication organization of the organizers of the "Dream Project" is not in place, and the lack of communication with the university (teaching point), especially the students, is not conducive to the effective implementation of the project. At the same time, the group organization's interest in the study, work, life and other aspects of the students is also obviously insufficient, which is not good for improving the satisfaction of running the project.

\subsection{Management services still need to be standardized}

The investigation and feedback show that the organizers of the "Dream Project" also have some shortcomings in their work. For example, the charges for privately-run schools are not standardized, which leads to the opinions of some students. More students are working on the school. The main reason for the dissatisfaction of management norms is that the contractors are uneven. Many private organizations obtain project contracting rights through public relations, only pay attention to market promotion, and do not pay attention to standard management and school quality.

\section{Analysis on the Market Optimization Countermeasure of Cultivating New Generation Industrial Workers in "Dream Project"}

In view of the problems existing in the current "Dream Project" training for the development of new generation industrial workers, the following optimization measures should be taken:

\subsection{Strengthening the in-depth promotion of the project}

In the implementation process of the "Dream Project" of the new generation of industrial workers, there is a problem of asymmetry of the beneficiaries. The project organizer and the organizer should 
further carry out the work, especially to strengthen the in-depth promotion of the project, so that the project can penetrate various industries and fields. Facing the city, it will go deep into the grassroots level and broaden the breadth and depth of the project development, so that the project implementation information will be radiated to every new generation of industrial workers.

\subsection{Strengthening the value guidance of the project}

Implementing the "Dream Project" new-generation industrial workers training project should start from the purpose of establishing correct participation, correct the misunderstanding of the utilitarianism of the new generation of industrial workers to participate in the purpose, strengthen the value guidance of the project, and enable participants to establish correct learning. Attitude, promote the new generation of industrial workers to learn through the "Dream Project", improve their skills and improve their quality.

\subsection{Strengthening the reform and innovation of the project}

It is necessary to scientifically analyze the shortages and needs of the new generation of industrial workers participating in the "Dream Project", carry out targeted training, and enhance the effectiveness of personnel training. The key point is to promote the growth of new generations of industrial workers and the improvement of skills. Participants learn a long way, learn to use it, improve their quality through learning, and promote their work in practice.

\subsection{Enhance the quality of the project}

The implementation of the "Dream Project" has been favored by enterprises and new generations of industrial workers. However, the quality of the project management needs to be improved and the project satisfaction is not high enough. This requires strengthening the quality control and improvement of the project, and it is necessary to comprehensively and comprehensively the "Dream Project" implements quality monitoring and check to ensure good recruitment, entrance examination, teaching implementation, management services, and graduation review. In particular, we must pay attention to the teaching of theory and practice, the organization and implementation of teachers and the evaluation of teaching effects, and improve the quality of teaching and the level of running schools.

\subsection{Sound scientific linkage mechanism}

The organizers of the "Dream Project" program should strengthen communication with all parties in the implementation of the project, establish a sound and scientific linkage mechanism, and establish a smooth and good platform for communication and communication among all parties so that problems can be discovered in time during project implementation. Analyze and solve problems. By establishing a linkage mechanism, it is also beneficial for the organizers to better understand the voices of the participants, better grasp and understand the demands of the new generation of industrial workers for study, work and life, and provide a scientific basis for project implementation and reform and innovation.

\subsection{Promote the standard operation of the project}

Many of the tasks implemented in the "Dream Project" program is organized and implemented by the project organizer, and the responsibility for standard operation is also implemented to the organizer. In practice, the organizer should strengthen the qualification review and selection of the organizer, and formulate a supporting supervision system to supervise the organizer's school-running behavior, and promote the standardized operation of the project through system management, daily monitoring, feedback supervision, etc., so that the project can continue to develop healthily.

\section{Conclusion}

In short, the "Dream Project" of the new generation of industrial workers is a significant project for 
people's livelihood. In the project development, it is necessary to pay attention to the real-time investigation and study of the implementation of the project. It is necessary to solve the shortcomings and problems in project implementation by strengthening the in-depth promotion of the project, strengthening the value guidance of the project, strengthening the reform and innovation of the project, strengthening the quality improvement of the project, improving the scientific linkage mechanism, and promoting the standardized operation of the project, which promote the healthy development of this project.

\section{Acknowledgement}

Project fund: This paper is to carry out the training of new generation industrial workers for the research projects of Guangdong Provincial Adolescent Education Association from 2018 to 2019, the research and Practice on the growth and development path of new generation industrial workers (2018 GJ060) and the adult education and scientific research program of Guangdong Provincial Adult Education Association (2018-2019). Research and Practice (Ycx181001) research results.

\section{Author information:}

Liao Yuanbing (1979 -), male, born in Heyuan, Guangdong Province, Vice Dean, Associate Professor and Master of Continuing Education College of Heyuan Vocational and Technical College, mainly studies adult education management and education market competition.

\section{Reference:}

[1] Yang Danyu, New Generation Industrial Workers'Dream-fulfilling Plan and Its Perfecting Path [J], Journal of Dongguan Institute of Technology, 2014 (04): 121-124

[2] [3]Che Ming Dynasty, Guangdong Dream-fulfilling Plan: Making the Dream-Bearing Development Write for Life [J], China Vocational and Technical Education, 2013 (04): 17-24

[4] Li Yanzi, Education and Training of New Generation Industrial Workers 